\title{
Cielo e inframundo en la cosmovisión mexica: análisis iconográfico
}

José Alcina Franch

Universidad Complutense. Madrid

Tomando como base los conceptos fundamentales en torno a la cosmovisión de los pueblos nahuas del centro de México, que en ocasiones llegan hasta nuestros dias, se analizan iconográficamente una serie de esculturas y relieves mexicas o aztecas, en los que se puede apreciar una división tripartita del mundo -cielo, superficie terrestre e inframundo- destacándose como elementos iconográficos muy significativos: el disco solar, con o sin la expresión de los cinco soles o eras cosmogónicas, como emblema del cielo y la diosa Itzpapálotl, como símbolo del inframundo.

En varias publicaciones recientes ${ }^{1}$ me he ocupado de revisar algunos conceptos ya clásicos en relación con la cosmovisión mexica o azteca, haciendo algunas nuevas proposiciones al respecto y recuperando del pasado algunas otras que convenían a mis planteamientos actuales. En el presente ensayo voy a ocuparme de la cuestión, considerando las "partes" del mundo -especialmente el cielo y el inframundo- como un todo y no como partes que pueden subdividirse a su vez en niveles o escalones - trece y nueve respectivamente - orientados en sentido vertical o en forma piramidal.

En realidad se trata de analizar e interpretar todo un conjunto de piezas escultóricas, muchas de las cuales fueron descritas y estudiadas por Nelly Gutiérrez Solana en un capítulo titulado "Piezas de forma cuadrangular y de forma cilíndrica" dentro de su, por otra parte, excelente libro sobre Objetos ceremoniales en piedra de cultura mexica. ${ }^{2}$ Dichas piezas, como veremos enseguida, han podido

1 Alcina Franch, José: La cosmovisión mexica en el contexto de Mesoamérica. "Congreso de Historia del Descubrimiento". Vol. 1, págs. 241-284. Madrid, 1992. Idem: "En torno a la cosmovisión mexica: viejas ideas, nuevas hipótesis". Homenaje a Jacques Soustelle. París (en prensa).

2 Gutiérrez Solana, Nelly: Objetos ceremoniales en piedra, de cultura mexica. México, 1983, págs. 123-153. 
tener función muy diferente, pero aquello que nos interesa destacar en este momento es que en su ornamentación se describe el mundo en esa división tripartita esencial: cielo, superficie terrestre e inframundo y en sus cuatro rumbos o soles principales, tomando el centro como lugar de comunicación arriba-abajo o como tiempo actual.

En un reciente estudio sobre la concepción del mundo según las informaciones proporcionadas por los curanderos del pueblo de San Miguel Tzinacapan, en la Sierra de Puebla, ${ }^{3}$ se hace una descripción en la que los tres niveles fundamentales del mundo se conocen con los nombres de in ilhuicac, in talticpac e in talocan. En el Talocan, la única planta que hay es un gran árbol situado en el centro, que sostiene a la tierra, aunque algunos curanderos dicen que hay otros cuatro árboles en las esquinas, cuyas hojas forman el suelo, mientras las ramas son las piedras. La comunicación con el inframundo se halla en el noroeste de la plaza, donde se sitúa un temazcal que permite el paso al mundo de los muertos o mictalli. "En los cuatro lados del inframundo se unen el cielo, ilhuicac, la tierra, talticpac, y el inframundo, talocan. Así se forman los límites de los cosmos y la unión esencial entre los tres niveles del mundo". 4

Por otra parte, los cuatro rumbos del mundo corresponden casi exactamente a la concepción prehispánica: el este y el oeste son los rumbos por donde nace y muere el sol cuyo curso nocturno es por el inframundo; mientras el norte representa la media noche o nadir y el sur es el cenit o momento más caluroso del día. ${ }^{5}$ La plaza del pueblo viene a ser la representación simbólica del centro del mundo, la iglesia se halla en el sur, el lugar de máxima luz o gracia, nexti, que como hemos dicho corresponde al cielo; la presidencia se sitúa en el norte o noroeste, que por lo tanto corresponde al inframundo o al mictlan. Pero en el centro del inframundo se halla otra iglesia, sin cruz ni campanas: es una cueva que va por debajo

3 Knab, Tim J.: Geografia del inframundo. "Estudios de Cultura Nahuatl". Vol. 21, págs. 31-57. México, 1991.

4 lbídem, pág. 44.

5 Ibídem, pág. 39. 
de la plaza, como la descubierta bajo la pirámide del Sol de Teotihuacan. "Es allí donde van los de talocan para rezar. La cueva es la residencia del taloc melaw o verdadero Señor del inframundo". ${ }^{7}$

\section{El mundo como un todo}

El conjunto de piezas cuyo análisis iconográfico vamos a realizar en estas páginas, representa un total de nueve, cuya forma y tamaño particulares son ordinariamente muy diferentes, pero cuya estructura es idéntica o muy similar. Todas ellas presentan tres planos: superior, lateral e inferior. En el plano superior hasta cinco de las nueve piezas presentan el emblema del "disco solar" en forma muy simple o muy compleja; en el plano lateral se ofrece una descripción de los tres niveles del mundo - celeste, terrestre e inframundo- siguiendo el modelo, muchas veces repetido en varios códices (Lám. 1), en el que se aprecia una banda superior con discos blancos u ojos como estrellas; dos bandas finas paralelas y pegadas una junto a otra en sentido horizontal y una banda inferior más ancha en la que se aprecian ojos "peciolados" y una figura que podría interpretarse como mariposa, Itzpapálotl, o planeta Venus. Esta división tripartita aparece en ocho de los nueve ejemplares seleccionados. Finalmente, en el plano inferior solamente hay decoración en uno de los ejemplares y se trata de una de las más típicas formas de Tlaltecuhtli o "monstruo de la tierra".

La lista de obras que vamos a utilizar como base para nuestro estudio, presentada en forma muy esquemática, es la siguiente:

1. Bloque cilíndrico con disco solar. Museo Nacional de Antropología (MNA). México. N. ${ }^{\circ}$ Cat.: $11-3345^{8}$ (Lám. 2).

6 Heyden, Doris: An interpretation of the Cave undemeath the Pyramid of the Sun in Teotihuacan. México. "American Antiquity." Vol. 40, n. ${ }^{\circ}$ 2, págs. 131-147. Salt Lake City, 1975.

7 Knab: Geografía..., pág. 45.

8 Alcina, J.; León-Portilla, M., y Matos, E.: Azteca. Mexica. Las culturas del México antiguo. Madrid, 1992, pág. 47. 
2. Altar de Venus (I). MNA. México. N. ${ }^{\circ}$ Cat.: 11-7029 ${ }^{9}$ (Láms. 3 y 4).

3. Altar de Venus (II). MNA. México. Citada por Gutiérrez Solana. ${ }^{10}$

4. Cilindro con banda celeste. Museo de sitio. Teotihuacan (México). "

5. Cilindro con disco solar y banda celeste. Philadelphia Museum of Art. Philadelphia. ${ }^{12}$

6. Piedra de Yale.-Disco solar, los cuatro soles y bandas celestes. Peabody Museum of Natural History, Yale University. New Haven. Conn. N. ${ }^{\circ}$ Inv.: $19.231^{13}$ (Láms. 5-6).

7. Recipiente cilíndrico con banda celeste y Tlaltecuhtli. MNA. México. ${ }^{14}$

8. Piedra de Tizoc. MNA. México. N. ${ }^{\circ}$ Cat.: $11-3425^{15}$ (Láminas 7-8).

9. Piedra del sol. MNA. México. N. ${ }^{\circ}$ Cat.: $11-3290{ }^{16}$ (Láminas 9-10).

Aunque en la serie de nueve piezas hay algunas variaciones apreciables, aún existen otros ejemplos que no hemos incluido en esta lista, pero que mencionaremos después, en los que la división tripartita no coincide con el modelo antes indicado ni siquiera lejanamente.

Si presentamos en forma de tabla las coincidencias observadas en esta serie de piezas, podremos apreciar más claramente la homogeneidad del conjunto.

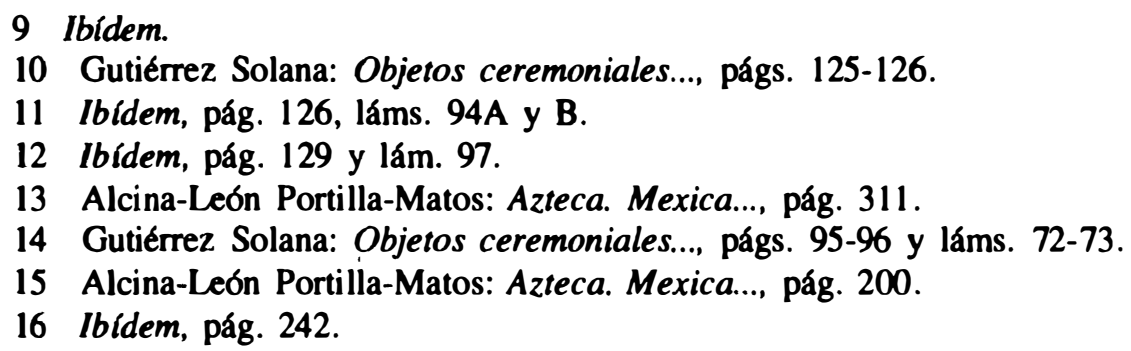


TABLA 1

\begin{tabular}{cccc} 
Pieza n. $^{\circ}$ & Disco solar & Tres niveles & Plano inferior \\
\hline 1 & + & + & - \\
2 & $?$ & + & - \\
3 & $?$ & + & - \\
4 & - & + & - \\
5 & + & + & - \\
6 & + & + & - \\
7 & - & + & $+^{*}$ \\
8 & + & + & - \\
9 & + & + & -
\end{tabular}

* Tlaltecuhtli.

\section{El "disco solar"}

Como acabamos de indicar, el emblema que conocemos como "disco solar" aparece en cinco de las nueve piezas seleccionadas, podría haber figurado en la número $2^{17}-$ y quizás en la que $\mathrm{Gu}$ tiérrez Solana dice que es idéntica - y no aparece en otras dos, una porque está destruida la parte superior y otra porque se trata de un recipiente y por lo tanto, ese plano superior no existe.

El disco solar, considerado como un "emblema" y no como una deidad, ha sido definido por Esther Pasztory, ${ }^{18}$ como un conjunto de círculos concéntricos atravesados generalmente por cuatro "rayos" o puntas de flecha que señalan los cuatro rumbos del mundo y en cuyo centro suele representarse un signo "ollin" o movimiento. En los ejemplos que hemos seleccionado, el número de círculos concéntricos es variable, dependiendo del tamaño y la complejidad del diseño.

17 Según se aprecia en la lám. 3, la cara superior del Altar de Venus (I) debía contener un relieve - probablemente el "disco solar"- pero éste fue "borrado" de manera que en este momento se aprecia un rehundido en esa zona; ese rehundido ha debido realizarse en época colonial.

18 Pasztory, Esther: Aztec Art. New York, 1983, pág. 81. 
Si el disco solar simboliza el "cielo", su contrario, el "inframundo" estaría representado por Tlaltecuhtli, el "monstruo de la tierra", que en este caso solamente aparece en la base de la pieza n." 7 . Sin embargo, este hecho es incierto, porque el "centro" del disco solar representa el centro del mundo a través del cual se comunica el cielo con el inframundo y, por lo tanto, a su través se puede ver el símbolo del centro o del inframundo. Es por eso que la mayor parte de los ejemplos mencionados representan el símbolo de "ollin" o quinto sol, el tiempo presente y el centro, pero algunas piezas llevan en ese lugar la imagen de Tlaltecuhtli o de Xiuhtecuhtli. La imagen de Tlaltecuhtli corresponde al rostro y las garras que se aprecian en la Piedra del Sol, según la interpretación de Navarrete y Heyden, ${ }^{19}$ mientras que el rostro de Xiuhtecuhtli se aprecia en el interior de la oquedad central de la llamada Piedra de Moctezuma ${ }^{20}$ (Lám. 11). En el caso de la Piedra del Sol, Tlaltecuhtli asoma su rostro desde el inframundo y muestra al mismo tiempo ambas manos, que como garras, apresan sendos corazones. ${ }^{21}$ Por su parte, en la Piedra de Moctezuma Ilhuicamina el rostro del dios Xiuhtecuhtli, dios del fuego relacionado con el anciano Huehueteotl, representa a su vez a la pareja de dioses generadores de todos los dioses, Nuestra Madre, Nuestro Padre, aquél que "está en el ombligo de la tierra, el que está en su encierro de turquesas". ${ }^{22}$ Una representación mucho más explícita y viva de esta imagen del mundo que nos proporciona la Piedra de Moctezuma, la hallamos en el folio 1-r del Códice Fejérváry-Mayer ${ }^{23^{\circ}}$ (Lám. 12).

Mencionar otras piezas en las que aparece el emblema del "disco solar" sería de poca utilidad, ya que son muy numerosas y en esos emblemas no apreciamos nuevos elementos que sean sig-

19 Navarrete, Carlos y Doris Heyden: La cara central de la Piedra del Sol: una hipótesis. "Estudios de Cultura Náhuatl". Vol. 11, págs. 355-376. México, 1974.

20 Solís, Felipe: "El temalacatl-cuauhxicalli de Moctezuma Ilhuicamina". En: Azteca. Mexica..., págs. 225-232.

21 Graulich, Michel: "La Piedra del Sol”. En: Azteca. Mexica..., págs. 291-295.

22 Códice Florentino. Manuscrito 218-20 de la Colección Palatina de la Biblioteca Medicea Laurenziana. 3 vols. México, 1979. Vol. 2, Lib. VI, fols. 7I-v.

23 León-Portilla, Miguel: Tonalamatl de los Pochtecas (Códice Mesoamericano "Fejérváry-Mayer"). México, 1985. 
nificativos para su mejor comprensión. No obstante cabe mencionar al menos otros cuatro ejemplos, a alguno de los cuales nos referiremos después. Así, el cuauhxicalli del Museo Británico, ${ }^{24}$ la pieza prismática del Museo de Historia Natural de Nueva York, ${ }^{25}$ el Teocalli de la Guerra Sagrada ${ }^{26}$ y la Piedra de los Cinco Soles de Rockford. ${ }^{27}$ Hay, naturalmente, otras numerosas representaciones de discos solares y sobre todo, del signo ollin o más específicamente 4 ollin, como representación del centro del mundo o de la era actual.

Es preciso destacar de inmediato que estas representaciones del "disco solar" tienen el doble valor de significar los cinco rumbos del mundo y asimismo las cinco "eras" cosmogónicas. Por eso, el centro está representado casi siempre por el glifo 4 ollin que es tanto como decir la era actual, pero al mismo tiempo las representaciones de Tlaltecuhtli o de Xiuhtecuhtli aluden al ombligo del mundo, al "centro" o lugar de intercomunicación entre el cielo y el inframundo.

De todas las piezas escultóricas mencionadas hasta ahora, nos interesa la información que nos proporcionan sobre rumbos y eras del mundo, la Piedra del Sol, la Piedra de Yale y la Piedra de Rockford.

Es bien sabido que la concepción mexica del espacio y del tiempo hacen, en la práctica, intercambiables unos conceptos y otros. Es lo que ocurre en la página 1 del Códice Fejérváry-Mayer, ${ }^{28}$ en la que la disposición es la equivalente a los cuatro rumbos del mundo y el centro en que aparece la figura de Xiuhtecuhtli, es decir, el espacio horizontal del universo mítico; sin embargo, al mismo tiempo que esto es así, se desenvuelven dos tonalpohualli: uno de ellos bordea los cuatro rumbos y los espacios intermedios señalando los glifos de cada uno de los días que inician las vein-

24 Baquedano, Elizabeth: Aztec Sculpture. Londres, 1984, pág. 84, y Pasztory: Aztec Art, pág. 236.

25 Alcina-León Portilla-Matos: Azteca. Mexica..., pág. 244.

26 Ibídem, págs. 236-239.

27 Nicholson, H. B.: Art of Aztec México. Treasures of Tenochtitlan. Washington, 1983, págs. 41-42.

28 León-Portilla: Tonalamatl..., págs. 28-31. 
te trecenas y otro, distribuido por rumbos desde el centro hacia el exterior, con los mismos veinte glifos, en la forma siguiente:

\begin{tabular}{llll} 
Oriente & Norte & Poniente & \multicolumn{1}{c}{ Sur } \\
\hline atl & ehécatl & quauhtli & tochtli \\
ollin & itzcuintli & calli & cozcaquauhtli \\
cóatl & técpatl & ozomatli & cuetzpalin \\
ácatl & miquiztli & quiahuitl & malinalli \\
cipactli & océlotl & mázatl & xóchitl
\end{tabular}

De ese modo, cada signo tiene la valoración que le da su orientación según el rumbo a que se adscribe. Algo semejante hallamos en las páginas 75-76 del Códice Tro-Cortesiano. ${ }^{29}$

Las tres piezas esculpidas antes señaladas, en las que en torno a un "disco solar" se señalan glifos correspondientes a las cinco eras o soles de la historia mítica de la humanidad se ordenan de la misma manera al tonalpohualli del Códice Fejérváry-Mayer. En este caso cada era, empezando por 4 Jaguar, se sitúa en cada uno de los cinco rumbos, según se aprecia en el esquema que viene a continuación y en el que se hace además, una comparación con el plano del mundo y los signos y colores atribuidos a cada dirección.

Se advierte que el orden de las eras o soles sigue la marcha contraria a la de las agujas del reloj, pero en cada piedra la colocación es diferente en el plano, lo que confirma el hecho de que tal posición es indiferente y lo que cuenta verdaderamente es el orden, que es siempre el mismo.

En el caso del quinto sol, apreciamos que, tanto en las tres piezas seleccionadas como en otras muchas en las que no se representan los cuatro soles o eras anteriores, viene siempre simbolizado por el signo 4 Ollin; únicamente en la Piedra del Sol o Calendario azteca se representa en el centro de ese signo el rostro de Tlaltecuhtli que aflora desde el inframundo a la superficie terrestre.

29 Ibídem, pág. 28. 


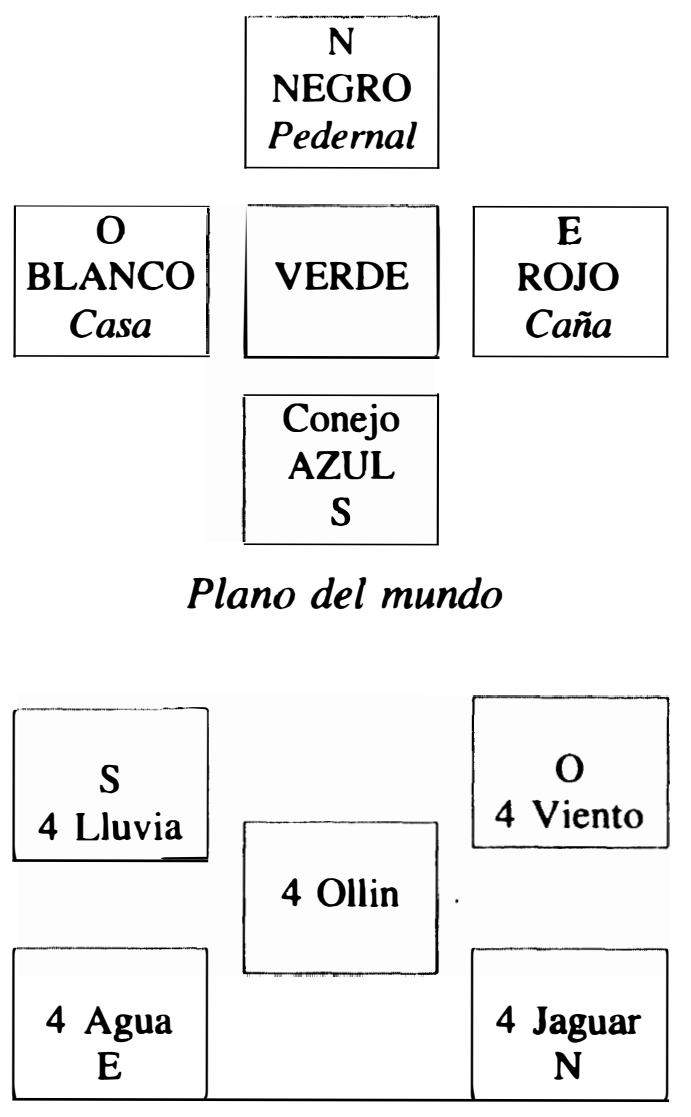

Piedra de Rockford

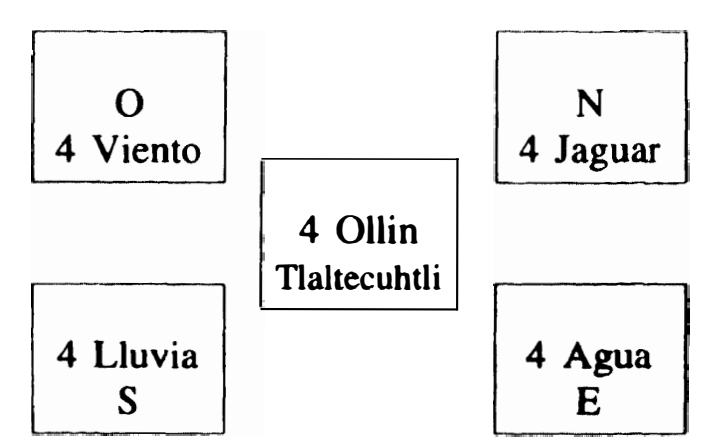

Piedra del Sol

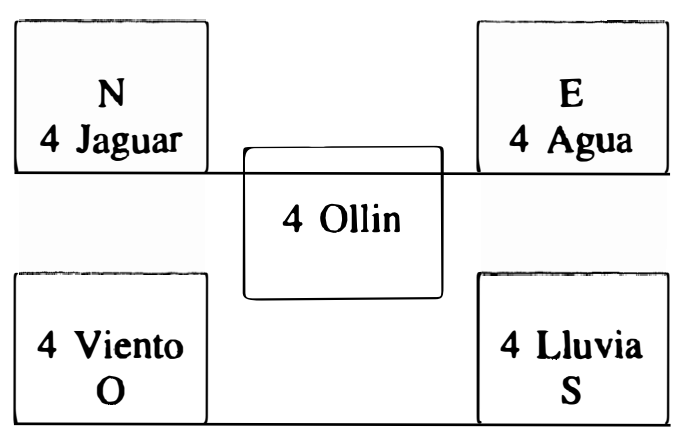

Piedra de Yale

\section{Los tres niveles del mundo}

Una vez que hemos analizado sucintamente la representación horizontal del mundo, mediante el emblema conocido como disco solar y su correlación espacio-temporal en los tres casos mencionados, podemos estudiar con un cierto detenimiento la ornamentación lateral de las nueve piezas seleccionadas en las primeras páginas de este ensayo.

Dicho perfil con los otros tres niveles señalados - cielo, superficie terrestre e inframundo- responde, como ya dijimos, a un modelo bastante común en los códices (Lám. 1) cuyas dos primeras partes no presentan demasiados problemas, pero si la terce- 
ra, el inframundo, especialmente por la presencia de la figura de Itzpapálotl.

Del conjunto de nueve piezas seleccionadas, solamente la pieza n. 8 no responde al citado modelo del Códice Borbónico; en todas las demás la parte superior está representada por una, dos o tres filas de discos destacados en relieve. Aunque, al parecer, ninguno de los discos de las piezas mencionadas contenía restos de pintura, si tenemos en cuenta que los que aparecen en el cabello de la Coyolxauhqui del Templo Mayor parece que estuvieron pintados de blanco, ${ }^{30}$ y así ocurre igualmente con los que decoran el tocado de Tezcatlipoca en la lámina 13 del Códice Borbónico, ${ }^{31}$ podemos suponer que los discos en cuestión estarían igualmente pintados en blanco sobre un fondo probablemente negro u oscuro, lo que en opinión de Carmen Aguilera representa un conjunto de estrellas que si las consideramos como los flecos que rodean al disco solar, vienen a representar, en conjunto, el mundo celeste.

La única pieza que no responde al modelo ya descrito es la llamada Piedra de Tizoc que, como es bien sabido, ofrece un lateral de extraordinario interés en el que al representar aquellos tres niveles del mundo, se atribuye a la franja superior —el cielo- una serie continua de representaciones en las que el elemento central es un diseño parecido al de la mariposa, con una estrella central y otras dos entre las alas (Lám. 13), que alterna con parejas de "ojos peciolados". La banda en cuestión se prolonga por todo el borde superior del tambor del cilindro de la Piedra de Tizoc.

La parte central, que debe representar la superficie terrestre, de acuerdo con el modelo señalado, está formada por dos cintas estrechas yuxtapuestas, que en el caso del Códice Borbónico reciben los colores amarillo (la cinta superior) y rojo (la cinta inferior) y en el caso de los ejemplares esculpidos en piedra no tienen color o no lo conservan al menos. Al igual que en el caso de la banda celeste, la única pieza que no responde a ese modelo es la misma Piedra de

30 Aguilera, Carmen: "Reconstrucción de la policromía de Coyolxauhqui". De la Historia. Homenaje a Jorge Gurría Lacroix, págs. 45-65. México, 1985, pág. 53.

31 Paso y Troncoso, Francisco del: Códice Borbónico: Manuscrito mexicano de la Biblioteca del Palais Bourbon. México, 1979. 
Tizoc, en la que se representa la serie de conquistas del pueblo mexica hasta el momento de la entronización del tlahtoani Tizoc. ${ }^{32}$

\section{El inframundo y la figura de Itzpapálotl}

La parte más compleja en orden a su interpretación, corresponde a la banda inferior del lateral de las piezas seleccionadas, aquella a la que, en principio, hemos designado como el inframundo y que se halla sistemáticamente por debajo de las dos cintas -amarilla y roja en el caso del Códice Borbónico- yuxtapuestas en sentido horizontal.

Para la exposición que vamos a hacer del tema, analizaremos en primer lugar el contenido iconográfico de esa banda en ocho de las piezas seleccionadas - salvando la Piedra de Tizoc que ofrece de nuevo una realización diferente - y agregando una pieza más, ésta fragmentaria, pero que reproduce el mismo modelo iconográfico, el llamado "Fragmento de Venus". ${ }^{33}$

En todas las piezas mencionadas se trata de un diseño que, en principio, definiremos como "mariposa", que se repite, teniendo como elementos de separación o bien un cuchillo o tecpatl, o bien el llamado "ojo peciolado". Tanto en el interior como en el exterior de esos diseños aparecen frecuentemente ojos semicerrados que se interpretan ordinariamente como estrellas nocturnas, aunque metafóricamente puedan interpretarse como "luz" o "brillo".

El elemento fundamental y más característico de este diseño es lo que hemos denominado, en principio, "mariposa". Partiendo del estudio más general de José Luis Franco ${ }^{34}$ y del más específico de Alfonso Caso ${ }^{35}$ sobre el dios Mariposa, podemos referirnos directamente a los nueve casos que utilizamos para nuestro análisis, di-

32 Wicke, Ch.: Once more around the Tizoc Stone: a reconsideration. "Actas del XLI Congreso Internacional de Americanistas". Vol. 2, págs. 209-222. México, 1976.

33 Alcina-León Portilla-Matos: Azteca. Mexica..., pág. 48.

34 Franco, José Luis: Representaciones de la mariposa en Mesoamérica. "El México Antiguo". Vol. 9, págs. 195-244. México, 1959.

35 Caso, Alfonso: Una urna con el dios Mariposa. "El México Antiguo". Vol. 7, págs. 78-95. México, 1949. 
ferenciando tres partes en el diseño: a) boca, b) alas y c) adornos exteriores.

Hay que decir en primer lugar que todas las "mariposas" que estudiamos se hallan en posición invertida, es decir, lo que llamamos boca se halla inmediatamente por debajo de las dos cintas paralelas y yuxtapuestas que hemos interpretado como la superficie terrestre y, por debajo, se hallan las alas y los adornos. Este detalle es particulamente importante, por lo que luego diremos, ya que la posición respecto de esas bandas paralelas implica la situación de esta figura en el inframundo. Por otra parte, aunque según nos informa Sahagún ${ }^{36}$ hay "muchas maneras de mariposas en esta tierra y de diversos colores, muchas más que en España", por lo general la llamada mariposa de obsidiana ("itzpapálotl") que es la que parece representar este conjunto de diseños es, según Ángel $\mathbf{M}^{a}{ }^{a} \mathrm{Ga}-$ ribay "una mariposa negra, reluciente y nocturna del Valle de México" ${ }^{37}$ que se asocia con el fuego, ya que el símbolo del fuego es la mariposa ${ }^{38}$ y el fuego es, a su vez, un elemento inframundano, como lo es igualmente el hecho de que algunas mariposas se representen en la parte inferior de ciertas vasijas trípodes de estilo mixteco. ${ }^{39}$

En la parte nuclear de la figura, aquella que hemos llamado boca, observamos dos tipos de diseño relativamente diferentes. En, al menos tres de las nueve piezas seleccionadas, especialmente en los números 1, 2 y 7 (Láms. 2-4) se observa un labio de forma que recuerda el "mostacho" de Tláloc, con tres dientes más o menos largos. En conjunto, la boca en cuestión, como era el caso de la de Tláloc, simboliza la cueva por donde el mundo celeste se comunica con el inframundo, es decir, las fauces que engullen a los muertos en su camino hacia el Mictlan. El segundo tipo de diseño para este sector nuclear es el ojo con su ceja, tal como aparece en el mo-

36 Sahagún, Fr. Bernardino de: Historia general de las cosas de Nueva España. Edición de Juan Carlos Temprano. 2 tomos. Madrid, 1990, lib. XI, cap. 5-11, pág. 846.

37 Sahagún: Veinte himnos sacros de los nahuas. Edición de A. M. Garibay. Informantes de Sahagún: 2. México, 1958, pág. 73.

38 Heyden, Doris: Una diosa con múltiples advocaciones. "Boletín del Instituto Nacional de Antropología e Historia", n. ${ }^{\circ}$ 37, págs. 51-54. México, 1958, pág. 51.

39 Franco: Representaciones de la mariposa..., pág. 215, lám. VII-1. 
delo del Códice Borbónico y también en el Calendario azteca y en el llamado Fragmento de Venus; en esos tres casos, como probablemente también en la Piedra de Yale, se trata de representar el ojo - estrella nocturna o brillo- de la mariposa o quizás una abreviatura de la boca-cueva de Itzpapálotl. Es, sin duda, el aparente parecido de ese ojo con su ceja, a la representación del planeta Venus lo que ha causado mayores confusiones en la interpretación de esta figura. ${ }^{40}$

Las alas de la mariposa se representan mediante una figura trilobulada cuyos ángulos resultan redondeados o angulosos, según los casos, pero cuyo interior suele estar dividido en dos mitades mediante un ojo peciolado con dos ojos semicerrados a ambos lados, lo que de algún modo da la falsa apariencia de un rostro, pero que, en realidad, sólo significa que las alas de la mariposa tiene estrellas nocturnas o brilla como las estrellas nocturnas, metáfora muy apropiada para la mariposa nocturna que es Itzpapálotl.

Finalmente, lo que hemos llamado "adornos exteriores" de la mariposa son diseños apuntados que se interpretan fácilmente como cuchillos o figuras de tecpatl que se clavan entre las alas de la mariposa. Esos cuchillos presentan unas veces el rostro característico de los cuchillos de sacrificio o bien una boca simplificada con tres dientes (Lám. 14).

$\mathrm{Si}$, para concluir esta exposición, comparamos las figuras analizadas con la placa de piedra (MNA. México. N. ${ }^{\circ}$ Cat.: 11-3278) interpretada generalmente como una imagen de Itzpapálotl, especialmente en lo que se refiere a las alas de mariposa y cuchillos de obsidiana que se aprecian en el contorno del rostro y las extremidades anteriores, veremos que tanto el perfil de las alas como la forma de los cuchillos es semejante a las de las piezas analizadas en las páginas anteriores, salvo en su número, que en la placa es mayor - hasta ocho lóbulos y otros tantos cuchillos- y en la posición de la figura que en el Museo Nacional de Antropología de México se ha colocado como divinidad descendente pero que muy bien podría estar en la posición contraria (Lám. 15).

40 Caso: Una urna..., pág. 93 y figs. 19-20. 
Para comprobar hasta qué punto la posición de la mariposa y los detalles de los cuchillos son importantes para interpretar la figura en sí, basta comparar estas figuras con la que aparece en el Códice Nuttall, lám. 10. ${ }^{41}$ En ese diseño apreciamos sobre un cielo nocturno la imagen descendente de un ser mítico en forma de mariposa, sin cuchillos de obsidiana y con un rostro de calavera que cabría interpretar como una de las famosas y terribles tzitzimime del fin del mundo.

De los numerosos poemas o himnos recogidos por Sahagún, mediante sus informantes, hay dos que se refieren a la diosa Itzpapálotl. El primero dice así:

"La diosa está sobre el redondo cacto.

¡Es nuestra Madre, Mariposa de Obsidiana!

Oh, veámosla:

en las Nueve Llanuras

se nutrió con corazones de ciervos.

¡Es nuestra Madre, la Reina de la Tierra!". ${ }^{42}$

Según este poema está plenamente justificado considerar a esta diosa formando parte del grupo de divinidades femeninas del grupo de Teteo inan $^{43} \mathrm{y}$, sin duda, muchas veces se confunde con Tlaltecuhtli, por ejemplo, en la figura central de la Piedra del Sol, que sostiene con sus garras dos corazones, o en la forma como se le representa en la plataforma que estudiaremos en las páginas siguientes. Ya hemos dicho que en opinión de Garibay, la obsidiana es una metáfora que destaca la negrura de las alas de la mariposa nocturna, que brilla como las estrellas en la noche ${ }^{44}$ y al mismo tiempo el hecho de que se muestre como en la placa antes citada, al modo de Tlaltecuhtli, asimila a esta diosa con todos los dioses del inframundo. ${ }^{45}$

41 Miller, Arthur G.: The Codex Nuttall. New York, 1975.

42 Sahagún: Veinte himnos..., pág. 67.

43 Nicholson, H. B.: "Religion in Pre-Hispanic Central México". Handbook of Middle American Indians, Vol. 10, págs. 395-446. Austin, Texas, 1971, págs. 420-421.

44 Sahagún: Veinte himnos..., pág. 73.

45 Kendall, Jonathan: The thirteen volatiles representation and symbolism. "Estudios de Cultura Nahuatl", Vol. 22, págs. 99-131. México, 1992, pág. 117. 
El comienzo del segundo poema dice así:

“-¿Dónde vais?, ¿dónde vais?

- iA la guerra, al agua divina:

Allí tiñe a los hombres

nuestra Madre Itzpapálotl

en el campo de batalla". ${ }^{46}$

No es extraño que una divinidad tan directamente relacionada con la muerte y con las Nueve Llanuras del Norte, participe en la batalla, en la guerra, buscando el agua divina, la sangre y la desolación.

De otra parte, sin embargo, Itzpapálotl debe situarse en el lado de las mujeres, en el oeste, en el Cihuatlampa, ya que, con frecuencia, la vemos en varios códices acompañada por un árbol roto, símbolo de Tamoanchan. ${ }^{47}$

Finalmente, Itzpapálotl está íntimamente relacionada con las cihuateteo y los tzitzimime. Al igual que Cihuacóatl-Quilaztli y Tlazoltéotl, es la patrona de las mujeres muertas en el parto y divinizadas, las cihuateteo o cihuapipiltin. ${ }^{48}$ En los códices se les suele representar con el cuerpo rayado en rojo y blanco, al igual que los tzitzimime y otras divinidades. ${ }^{49}$

De la serie de representaciones del inframundo que acabamos de estudiar, es una excepción la que figura en la parte inferior del cilindro de la Piedra de Tizoc. En efecto, en este caso, los personajes que se enlazan en las escenas de conquistas sucesivas del pueblo azteca se asientan sobre una superficie que corresponde al inframundo que, en este caso, se ha representado como sucede en múltiples ocasiones en los códices, sobre las fauces abiertas del "monstruo de la tierra" o Tlaltecuhtli. Entre las varias bocas se ha representado el cuerpo escamoso de ese monstruo terrestre mediante una serie de signos oblongos que representan las escamas.

46 Sahagún: Veinte himnos..., pág. 238.

47 Heyden, Doris: La Diosa Madre Itzpapálotl. "Boletín del Instituto Nacional de Antropología e Historia", n." 11, págs. 3-14. México, 1974, pág. 3.

48 Ibídem. Spranz, Bodo: Los dioses en los códices mexicanos del grupo Borgia. México, 1973, pág. 83.

49 Heyden: Ibídem, pág. 3. 
Hay que indicar, por último, que así como en la superficie superior - celeste - la mayor parte de los ejemplares seleccionados llevan el "disco solar", el Tlaltecuhtli característico para representar el inframundo en el plano inferior de muchas esculturas, en esta serie solamente aparece en la pieza $n .^{0} 7$, una especie de cuauhxicalli y excepcionalmente se asoma en el orificio central del signo 4 ollin de la Piedra del Sol o Calendario azteca.

\section{La plataforma de Itzpapálotl}

He dejado intencionalmente para un último lugar el comentario de una pieza que siendo excepcional desde muchos puntos de vista, se atiene a la división tripartita - cielo, tierra e inframundode todas las que hemos analizado en este estudio. Se trata de la que algunos han llamado "plataforma de Itzpapálotl", ${ }^{50}$ y a la que nos hemos referido en un trabajo anterior todavía inédito. ${ }^{51}$

Se trata de un bloque prismático de grandes dimensiones -0'78 × 0'63 × 1'00 m.- que se conserva en la galería inmediata a la Sala Mexica del Museo Nacional de Antropología de México $^{52}$ y en la que se aprecian: a) un lado superior (celeste); b) cuatro laterales (inframundanos), y c) un lado inferior (el agua primordial del inframundo).

El lado superior es de difícil interpretación, ya que al estar fragmentada la pieza no se ve por completo una posible figura de guerrero, de la que se aprecia con claridad un brazo cuya mano sostiene escudo y tres flechas $y$, en consecuencia, tampoco se puede explicar por qué el fondo de este relieve presenta ondas marinas semejantes a las del plano que suponemos inferior, en el cual en medio de esa representación del agua se observan huesos, cráneo, corazones y manos sangrantes.

50 Pasztory: Aztec Art, pág. 236.

51 Alcina, José: "El Agua primordial entre los mexica". Homenaje a Ignacio Bernal. México (en prensa).

52 Alcina-León Portilla-Matos: Azteca. Mexica..., págs. 300-301. 
Pero con independencia del significado de esos dos lados - superior e inferior- lo que nos interesa destacar ahora es que en los cuatro laterales se representa (Lám. 16) una imagen de Itzpapálotl, la mariposa de obsidiana que tiene en sus garras sendos corazones y cuyas alas se hallan decoradas con multitud de cuchillos de obsidiana. Si es correcta nuestra interpretación, la mariposa se halla mirando hacia el cielo - no es, pues, una divinidad descendente- y, como nuestra Madre, es la Tierra que flota -cual Cipactli- en las aguas primordiales de la creación rodeada de símbolos sacrificiales. Lo que para Esther Pasztory ${ }^{53}$ podría ser una referencia al culto de las tzitzimime, es para mi Itzpapálotl como diosa terrestre en el momento de la creación, en medio del agua primordial.

En conclusión, podríamos decir que los escultores mexicas y muy especialmente los tenochcas, con independencia de la función, la forma y el tamaño de las obras que tuviesen que realizar para los diferentes templos y lugares sagrados de la urbe, representaban con mucha frecuencia su arraigada e íntima manera de concebir el mundo, de tal manera que sus potenciales contempladores, cualquiera que fuese el ceremonial en que se hallasen involucrados, tuviesen presente ese esquema cósmico, en el que cada uno de ellos, ya fuesen pipiltin o macehualtin, tenían que jugar un mismo papel: nacer, vivir - " ¡sólo venimos a llenar un oficio en la tierra, oh amigos!"; "un instante muy breve goza de las flores primaverales"morir - "¡no se vive para siempre en la tierra!”- para volver a renacer - “Allá donde no hay muerte, allá donde se triunfa, allá vaya yo"- como rueda infinita. ${ }^{54}$

53 Pasztory: Aztec Art, pág. 236.

54 Los versos citados se han extraído de varios poemas recogidos en Alcina, J.: Mitos y literatura azteca. Madrid, 1989, págs. 53, 54, etc. 


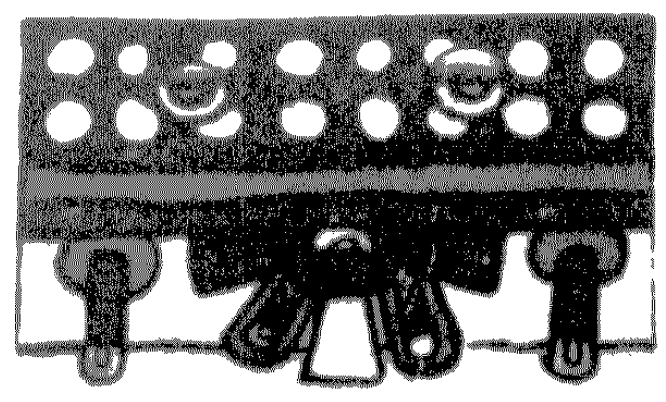

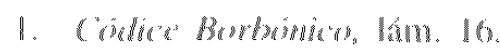

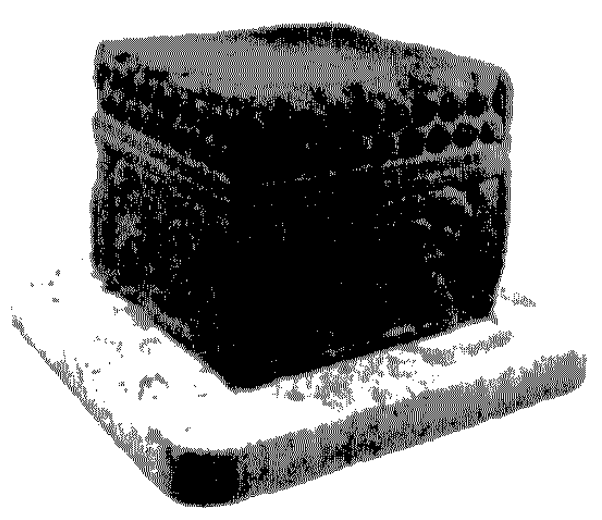

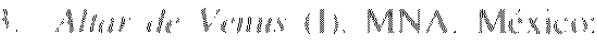

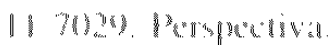

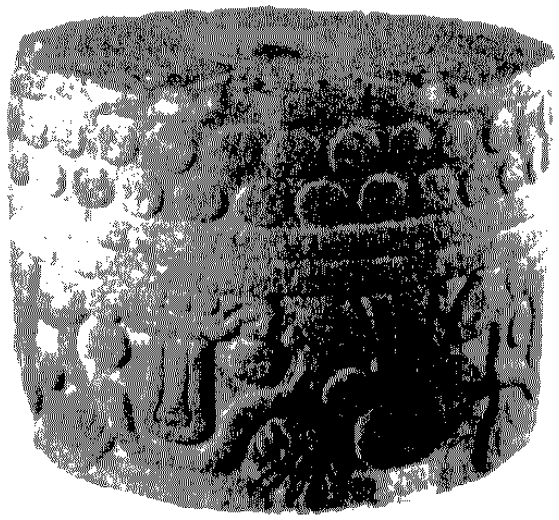

2. Bhouse "iflodrice con "disco solar". MNA. México: 11-3345.

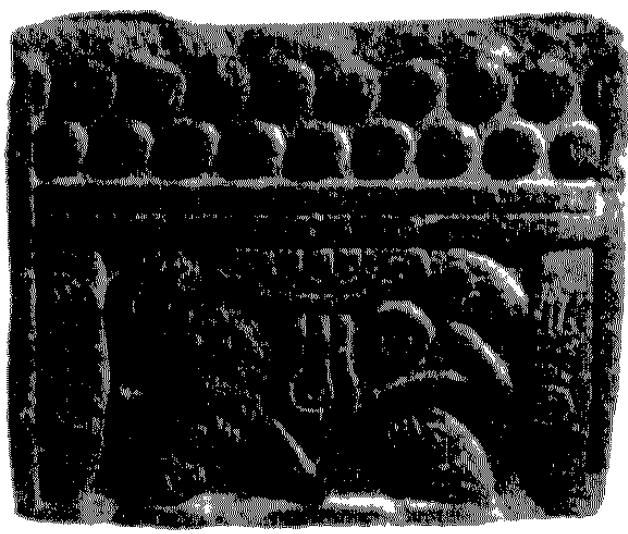

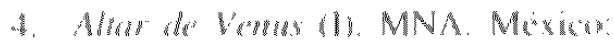
11.7120 . Vista laterist. 


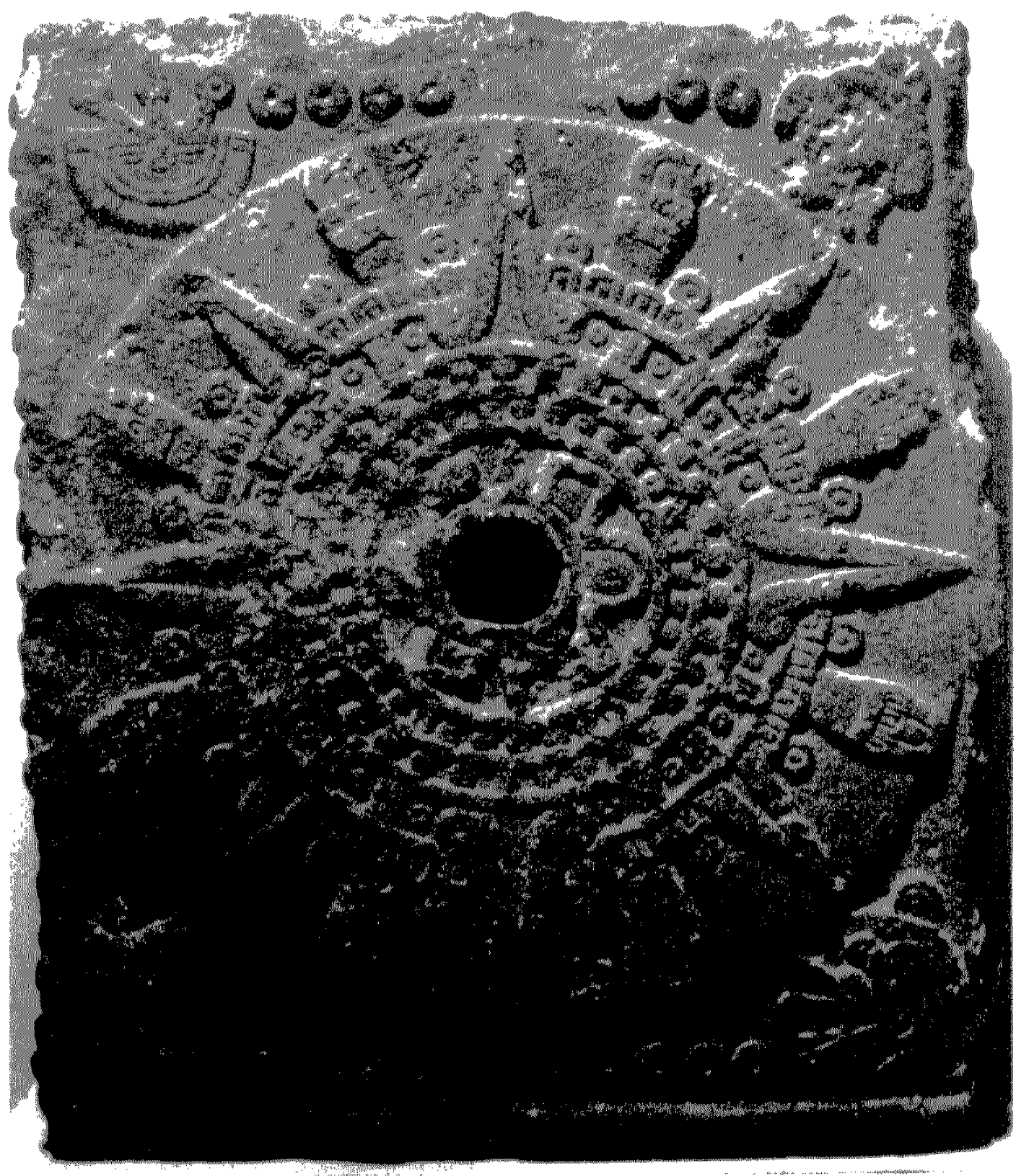

5. Piedra de Yule. Peabody Museum of Natural History. Yale I Iniversily. New Haven. Conn: 19,231. Vistat fromtall. 


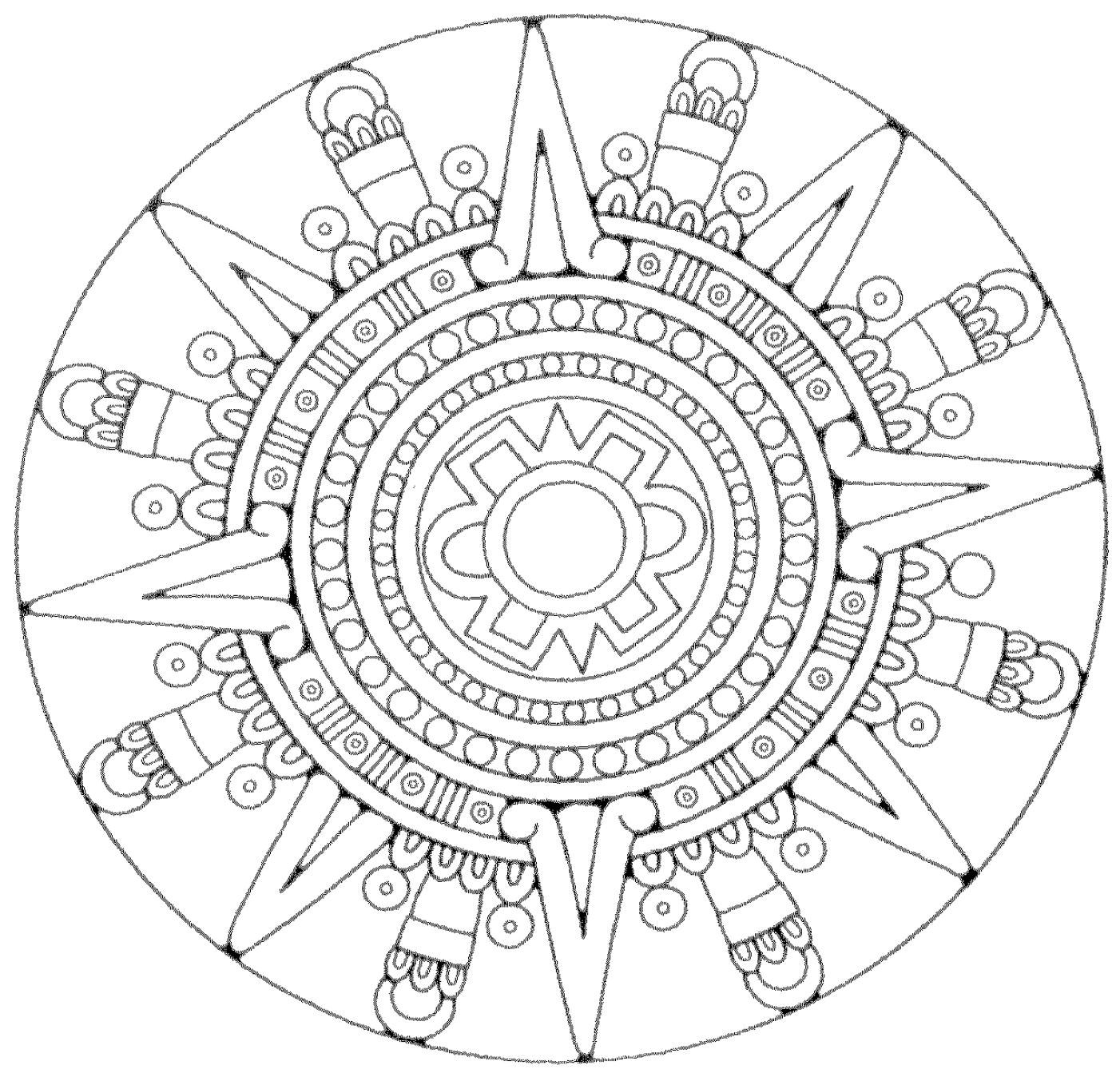

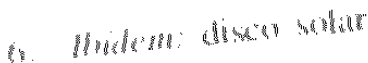




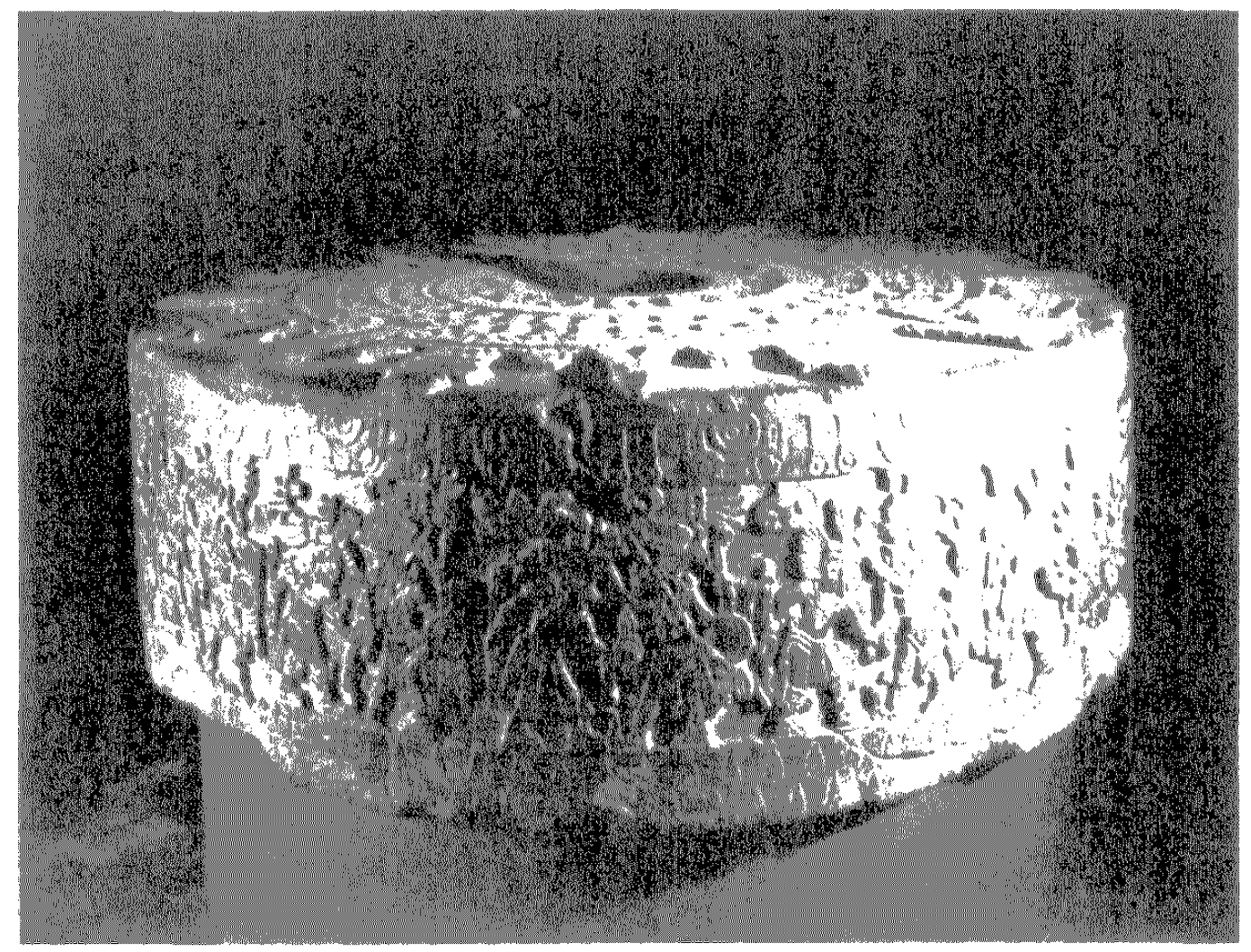

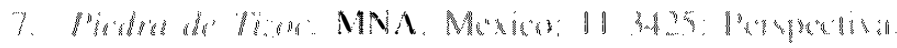




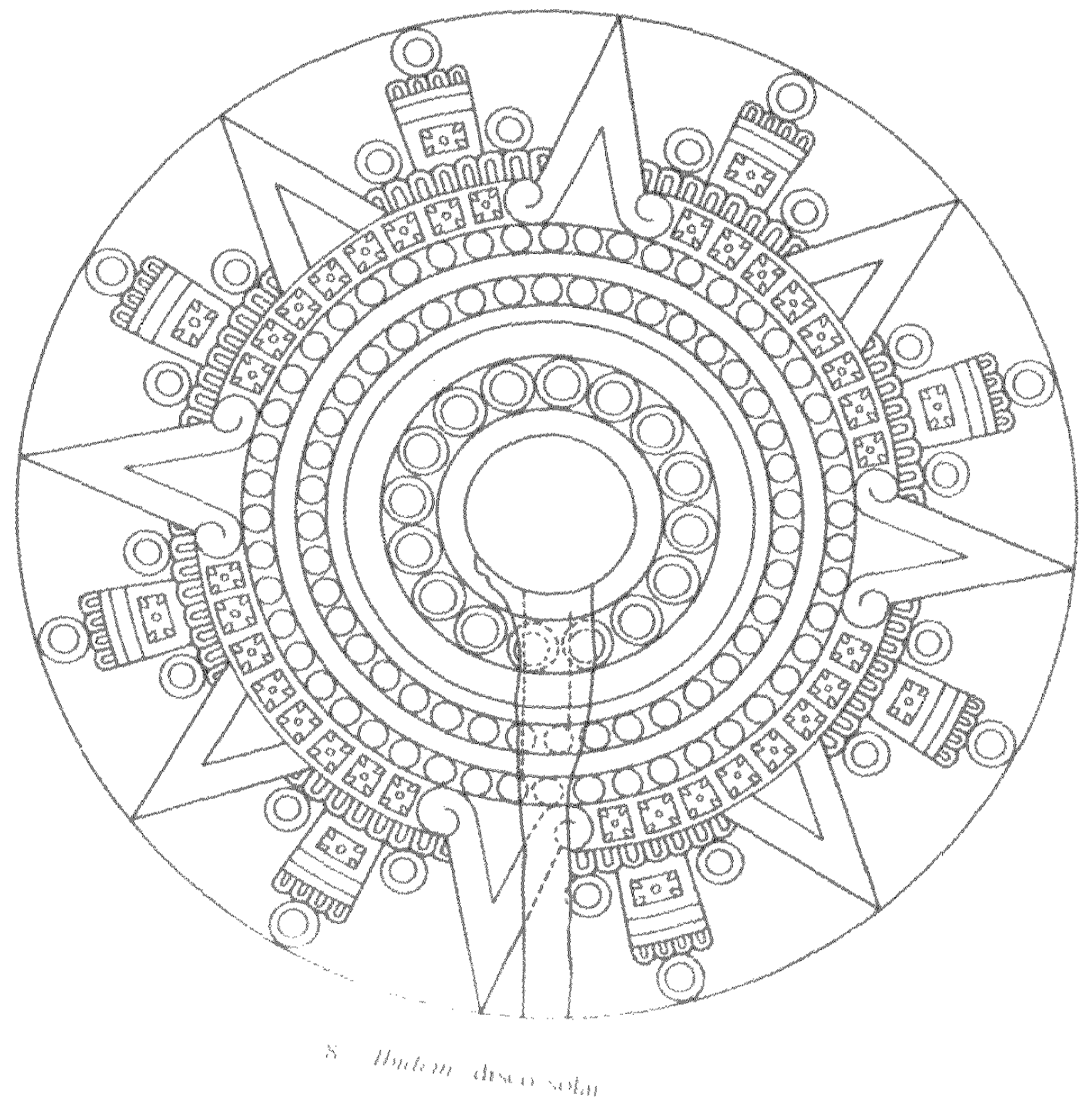




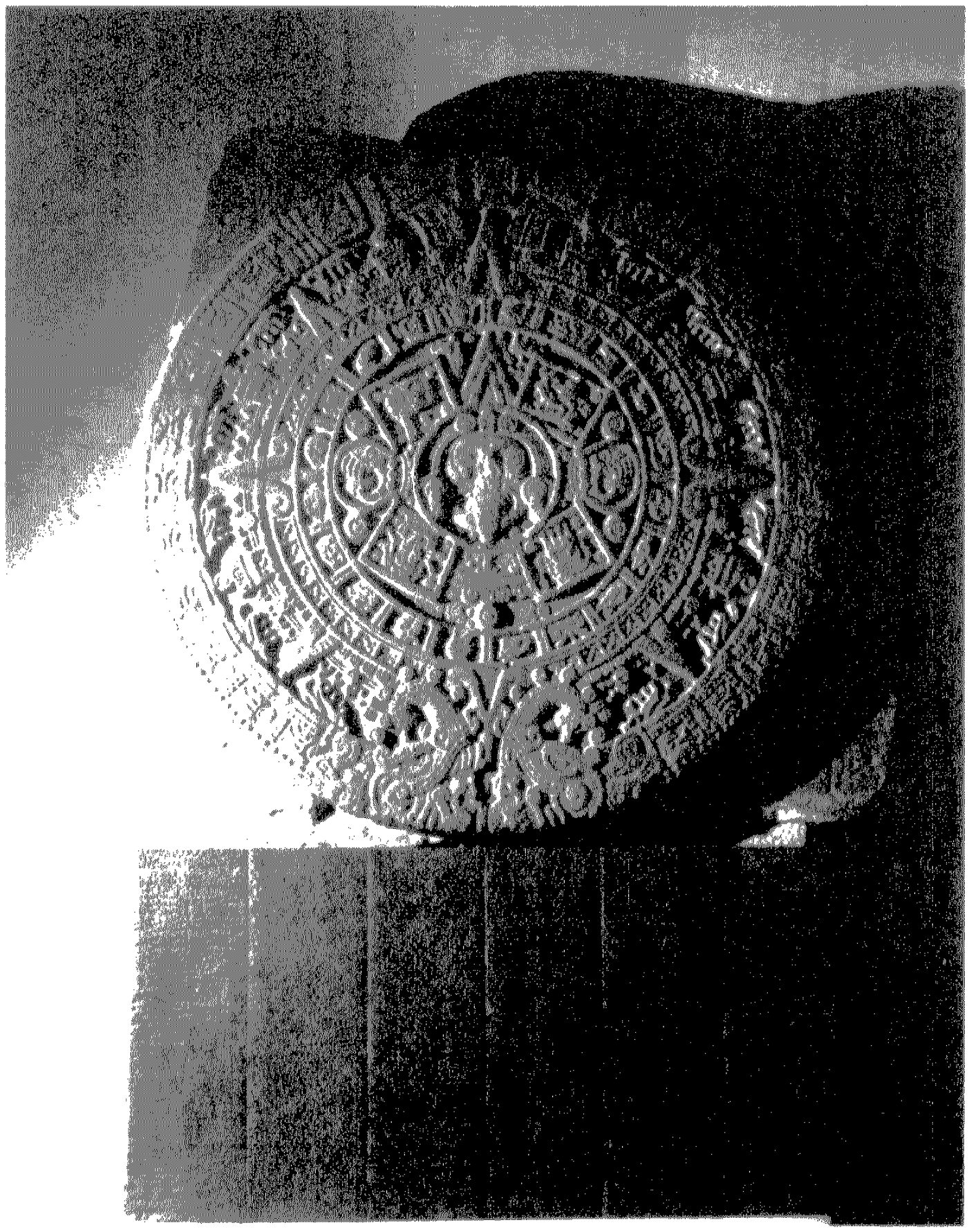

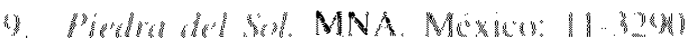




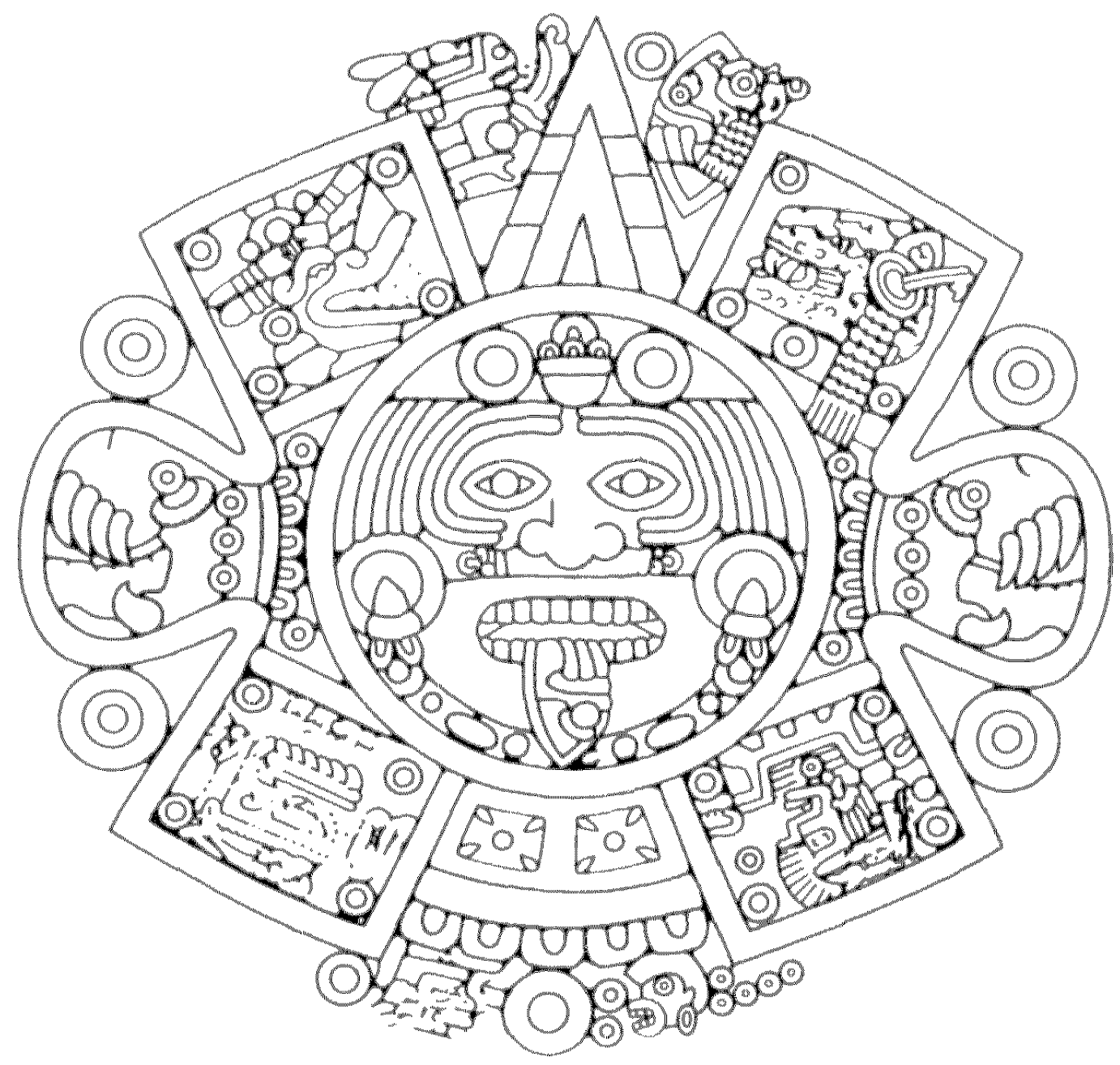

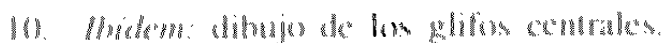




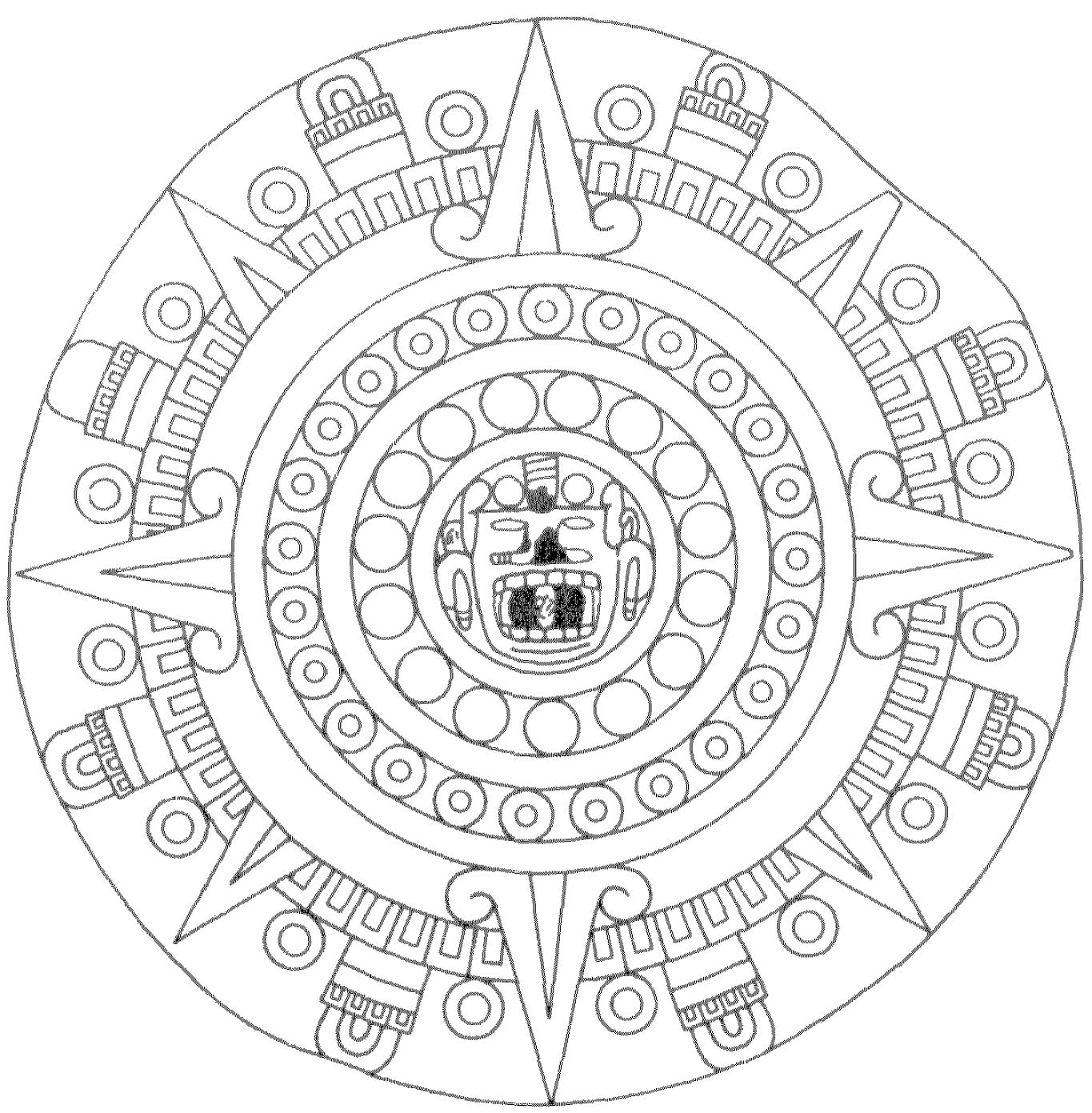

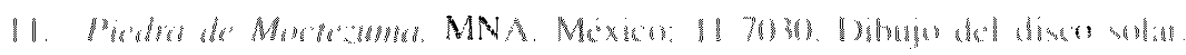




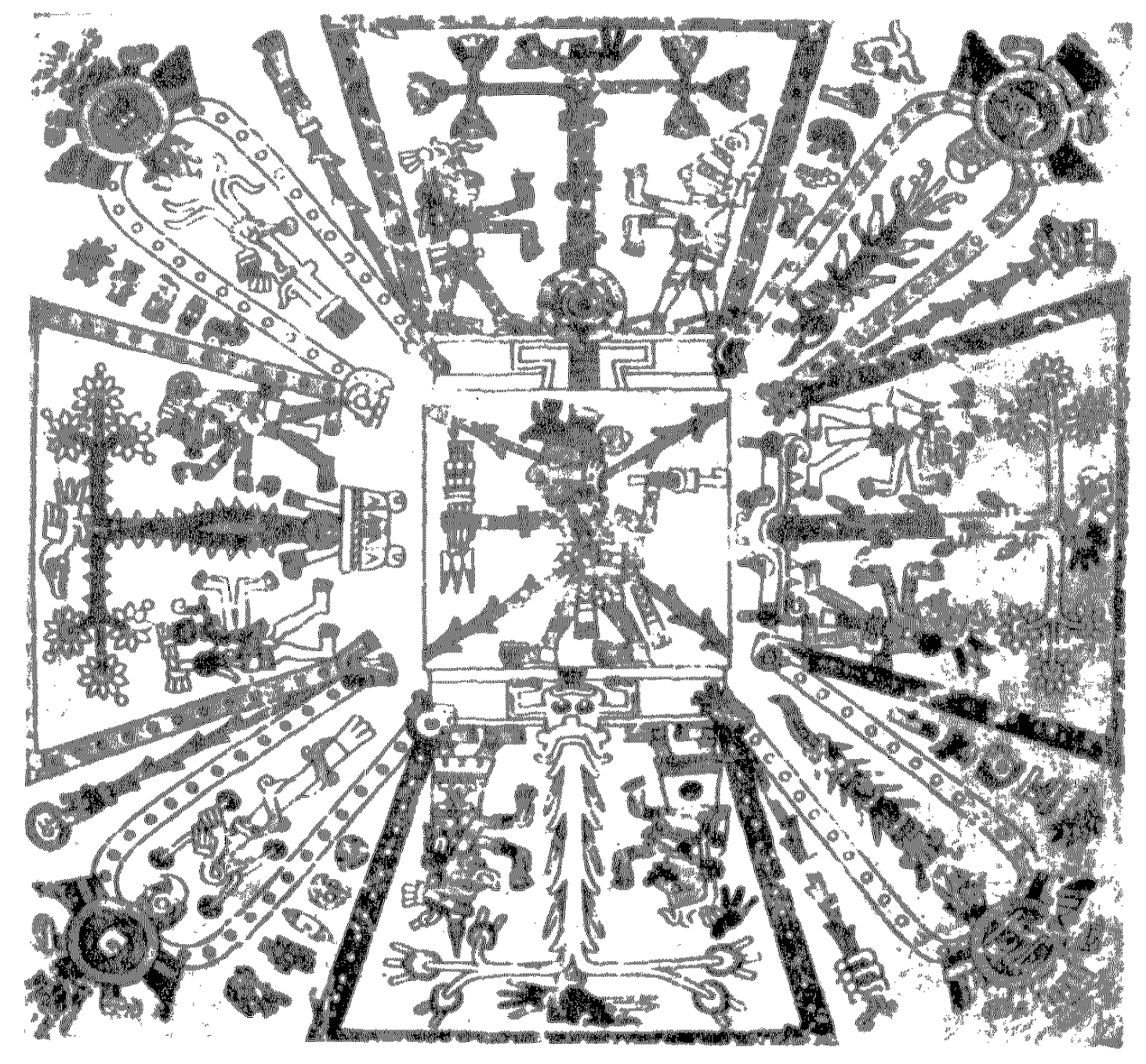

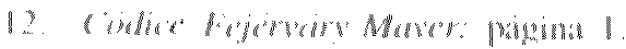




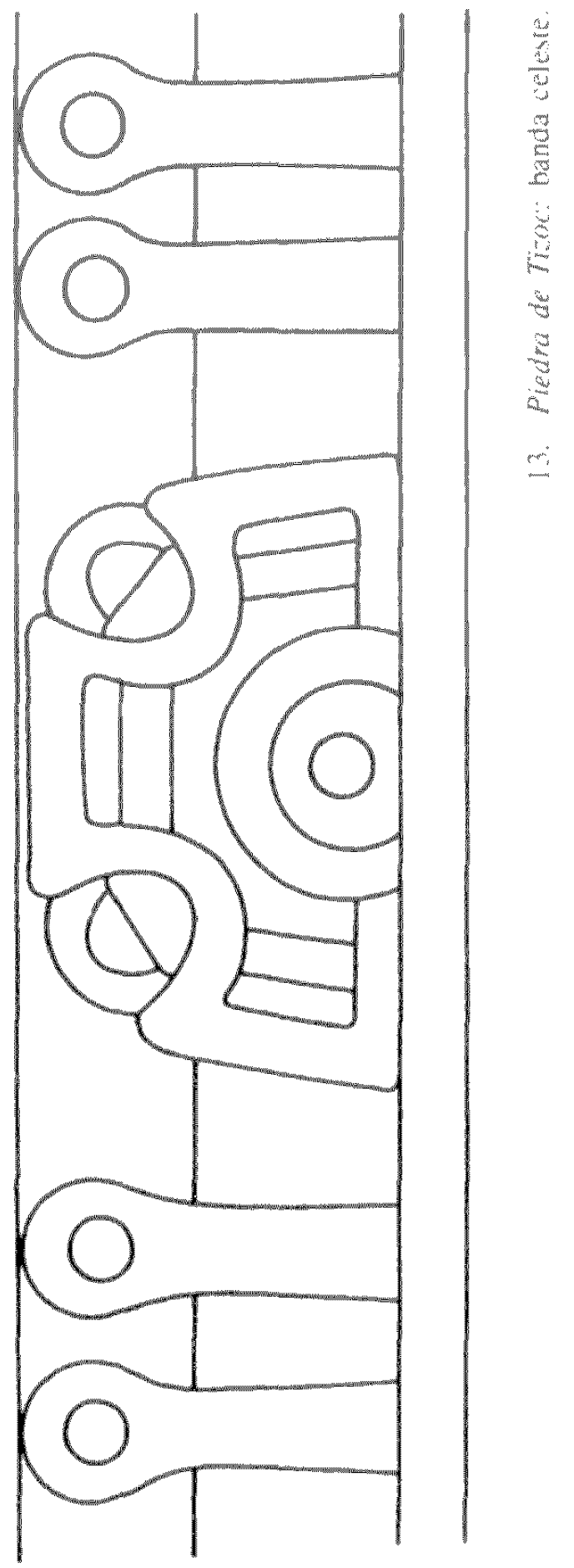




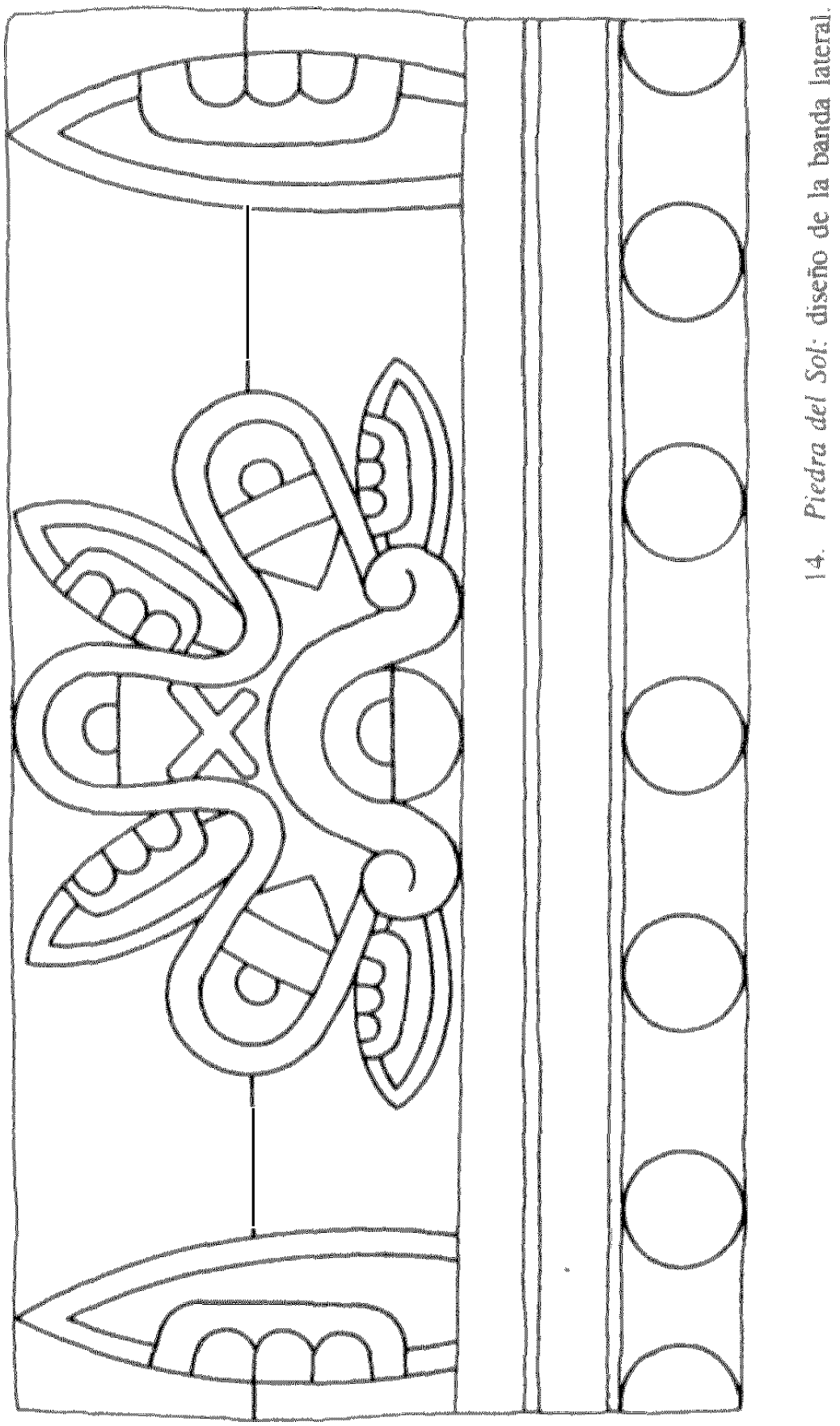




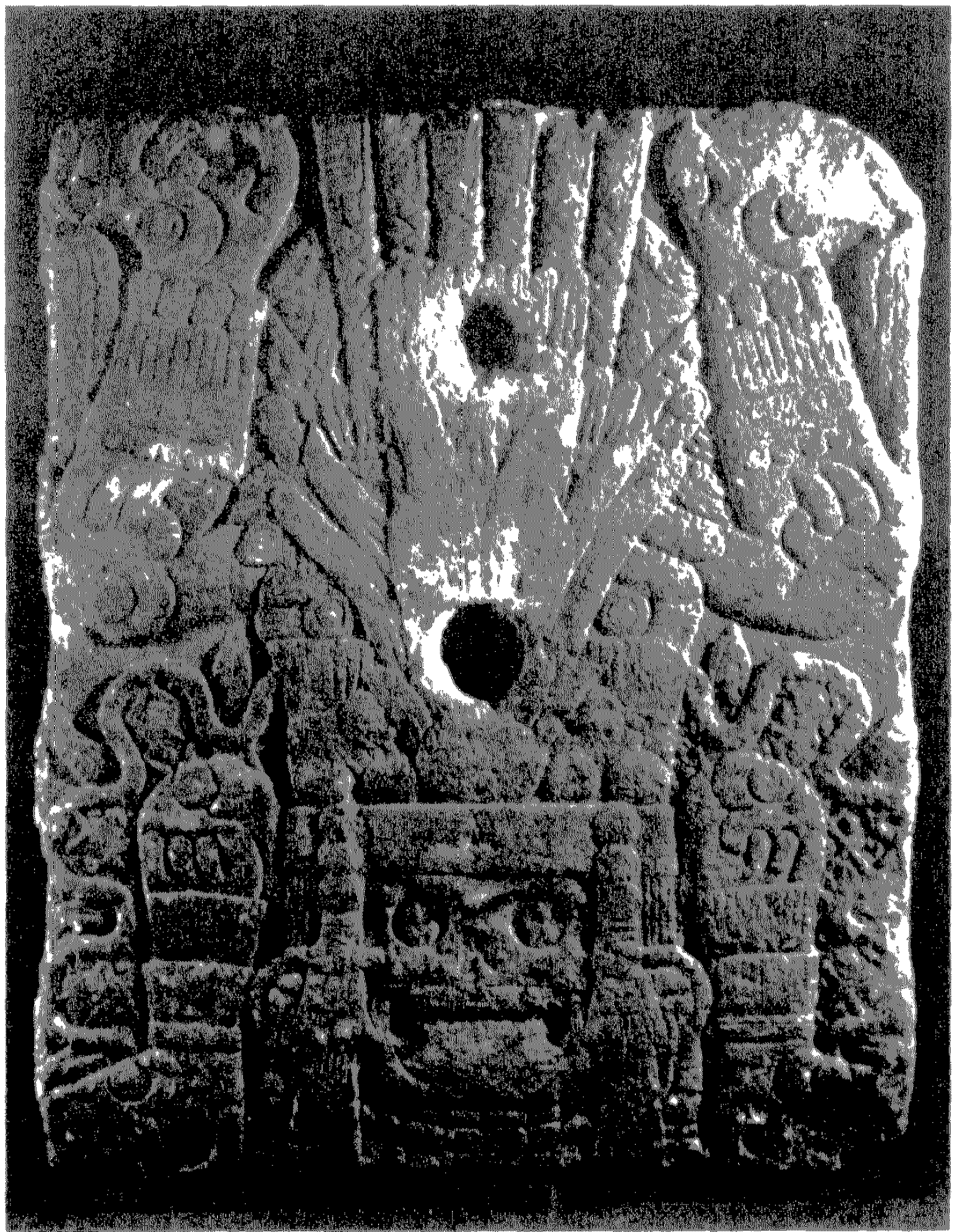

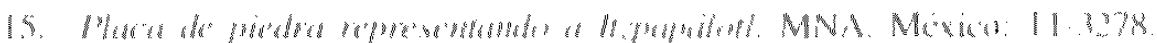




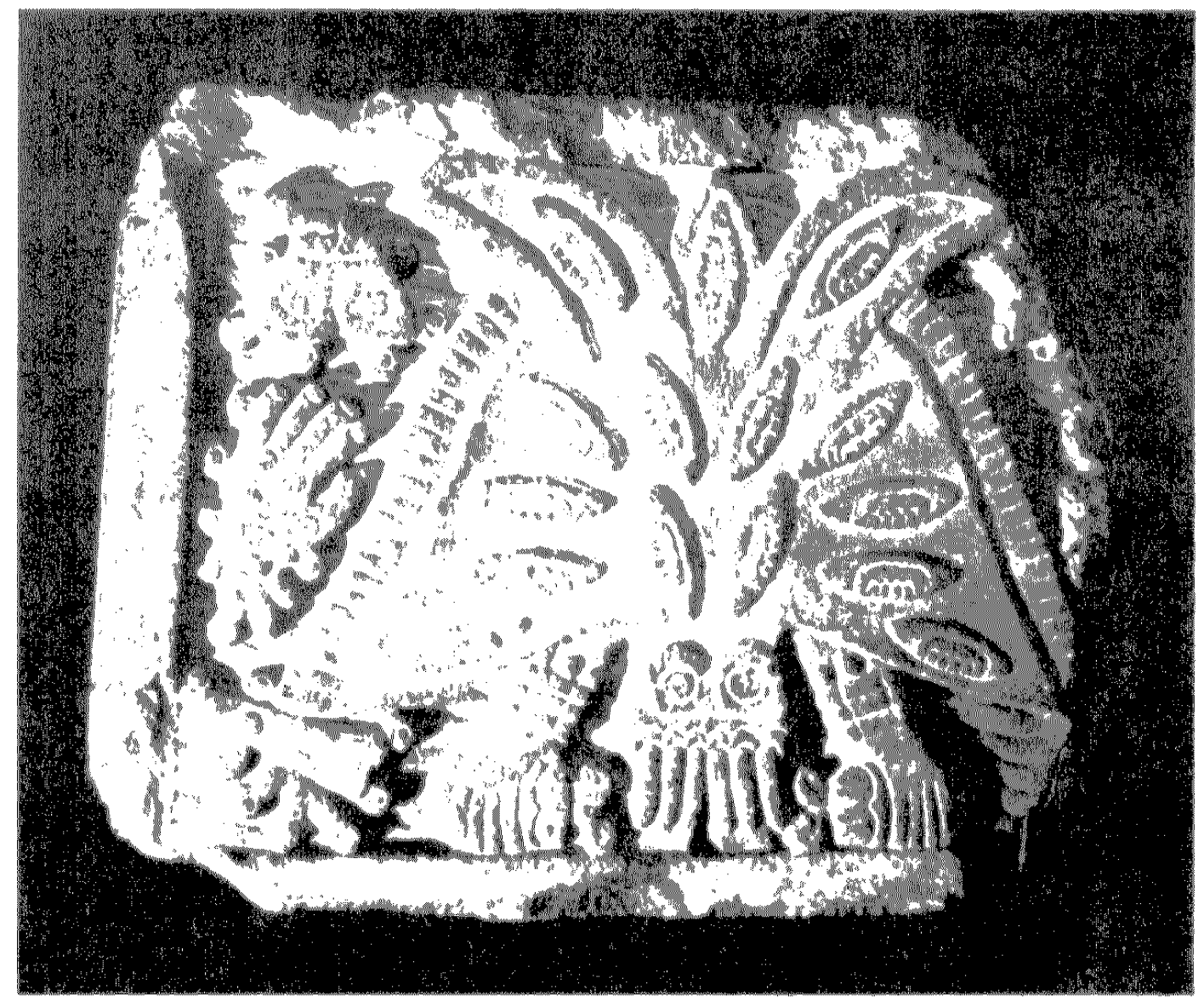

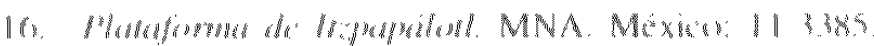

